\title{
Research on the Relationship Among Intelligence Capital, Corporate Diversification Strategy and Corporate Performance of Top Management Teams
}

\author{
Chuang Liu ${ }^{\mathrm{a}}$, Lu Mab \\ School of management, Guangxi University of Science and Technology, Liuzhou 545000, China; \\ a1925727865@qq.com, bmalu6655@163.com
}

Keywords: Top management team, intellectual capital, strategy, corporate performance.

\begin{abstract}
Good executive teams can develop the right strategies in the "weak context" of complex mutations to improve the company's dynamic adaptability. In this paper, the intellectual capital of senior management team will be defined based on the theory of echelon. Based on the perspective of enterprise diversification strategy, the internal mechanism of intellectual capital and enterprise performance of senior management team is explored.
\end{abstract}

\section{Introduction}

An excellent management team is the most valuable human resource for each company. Establishing and maintaining an effective senior management team can help businesses maintain core competencies in complex environments. Intellectual capital is an important strategic resource for the company, which can bring continuous performance to the company. Chinese scholars Zhu Jinwei (2017), Li Wenchang (2016), and Pan Ailing (2013) studied the relationship between intellectual capital and corporate performance from the demographic characteristics of the senior management team [1][2][3]. With the advancement of relevant research, some scholars have studied the intricate relationship between the intellectual capital of senior management teams and corporate performance based on strategic management perspectives. Foreign scholar Biagio Simonetti (2015) believes that the intellectual capital of the executive team plays an important regulatory role in the company's strategy (product diversification, international diversification) and corporate performance [4]. The internal relationship between Executive team intellectual capital, corporate strategy and performance requires further analysis and discussion. In view of this, this article will revolve around the relevant theories of the senior management team and review the relationship among the intellectual capital of the senior management team, corporate performance, and corporate strategy. This will open new ideas for the study of the intellectual capital of the senior management team.

\section{Related Research on the Intellectual Capital of Senior Management Team}

\subsection{Overview of Executive Team Intellectual Capital and Influencing Factors}

In recent years, scholars have begun to focus on the research field of the intellectual capital of senior management personnel. Mingjie Ming (2002) believes that team intellectual capital is an asset formed through the accumulation of knowledge and skills of the company. Li Dayuan (2008) explores the concept of the intellectual capital of the senior management team from the two dimensions of human capital and social capital in the intellectual capital[5], and believes that the human capital of the senior management team is mainly characterized by some demographic characteristics; the social capital of the senior management team is a member of the team and the collection of resources formed by formal and informal social relations in the organization[6]. By combing literature, researchers mostly theoretically explain the related concepts of the intellectual capital of the executive team from the group level.

At present, the structure dimension of intellectual capital of senior management team is defined based on the elements of senior management team. Previously, intellectual capital was generally divided into three levels of research. Tables, Pike, and Sofian (2012), Wall, Kirk, and Martin (2004) 
all pointed out that corporate intellectual capital consists of three parts: human capital, structural capital, and relational capital [7]. Thus, Li Dayuan (2008) believes that the intellectual capital of the executive team is the sum of the human capital and social capital owned by the top management of the company [5]. That is, the intellectual capital of the executive team does not only reflect the characteristics of the team members' human capital, but also the network of the team members. Therefore, this study divides the top management team's intellectual capital into two dimensions: human capital and relational capital.

The cultural environment at the macro level is an important factor affecting the intellectual capital of the senior management team. Bonitos (2001) put forward the cultural environment in which the company is located is the factor that has the greatest impact on the intellectual capital of the company in all macro factors. James (2006) found that the corporate culture environment plays a decisive role in the formation and management of the intellectual capital of the senior management team. In addition, the organizational internal management mechanism is another important factor affecting the intellectual capital of the senior management team. Huselid (1997) found that personnel deployment can eliminate negative factors in the organization and keep the organization in a harmonious and stable open environment. Promoting the promotion of relationship capital can form a good organizational communication mechanism.

\section{The Relationship Among the Intellectual Capital, Corporate Strategy and Corporate Performance of the Senior Management Team}

\subsection{Executive Team Intellectual Capital and Corporate Performance}

Human capital is a key element of team intellectual capital and can provide enterprises with longterm developmental momentum. Carmen et al. (2015) pointed out that the heterogeneity of top management team's human capital is positively related to corporate performance in terms of demographic characteristics (age, education) and management experience heterogeneity (function, industry, and international diversity) [4]. In terms of domestic research, Chen mengyuan and tang guiyao (2016) believe that high level human capital can help senior management team develop effective business strategies, thus achieving the goal of optimizing corporate performance [8]. In short, high-level senior management teams can maintain a high level of consistency with the organization in implementing strategic decisions and provide intellectual support for improving corporate performance.

The senior management team builds the network resources required for the development of the company by it self's relationship capital to achieve innovation in corporate performance. Calabrese and Silverman (2000) used entrepreneurial social networks to replace entrepreneurial social capital and used network theory to reveal the creation, survival, and growth of new businesses. Peng (2004) elaborated the effect of social capital on corporate performance from the perspective of entrepreneurial social capital affecting the company's intellectual capital. Chinese scholar Zhuang Jincai (2012) used entrepreneur-based social networks as the entrepreneur's social capital to reveal the social connections between the members of the senior management team and the external environment [9].

\subsection{Corporate Diversification Strategy and Corporate Performance}

At present, the research on the relationship between diversification strategy and enterprise performance has not reached a unified conclusion. On the one hand, some studies reveal the negative correlation between diversification strategy and corporate performance. Chakrabarti et al (2007) found that as the degree of diversification of enterprises deepens, corporate performance will show a downward trend. On the other hand, some scholars have given different views on the relationship between corporate diversification strategy and corporate performance. Yu Pengyi et al (2017) found that companies which with high degree of diversification will have a high level of economic benefits [10]. In addition, the initial relevant research that explores corporate performance only based on the corporate diversification strategy itself. Subsequently, many scholars began to pay attention to the impact of different types of corporate diversification on corporate performance. 


\subsection{The Influence Mechanism of the Intelligence Capital of Senior Management Team on Corporate Strategy and Corporate Performance}

The senior management team with high intellectual capital level has the skill, unique knowledge and creative thinking, as well as the accurate prediction ability. This is critical for companies to respond to external opportunities and challenges. The company's "brains" develop appropriate development strategies, Improve the level of corporate performance. It can be said that the intellectual capital of the senior management team can influence the growth of corporate performance by influencing corporate strategy. By sorting out the top management team's intellectual capital, corporate diversification strategy and relevant literature on corporate performance, this paper finds that the executive team's intellectual capital, such as knowledge and skills, is crucial to the successful implementation of the company's strategy and can drive the improvement of organizational performance.

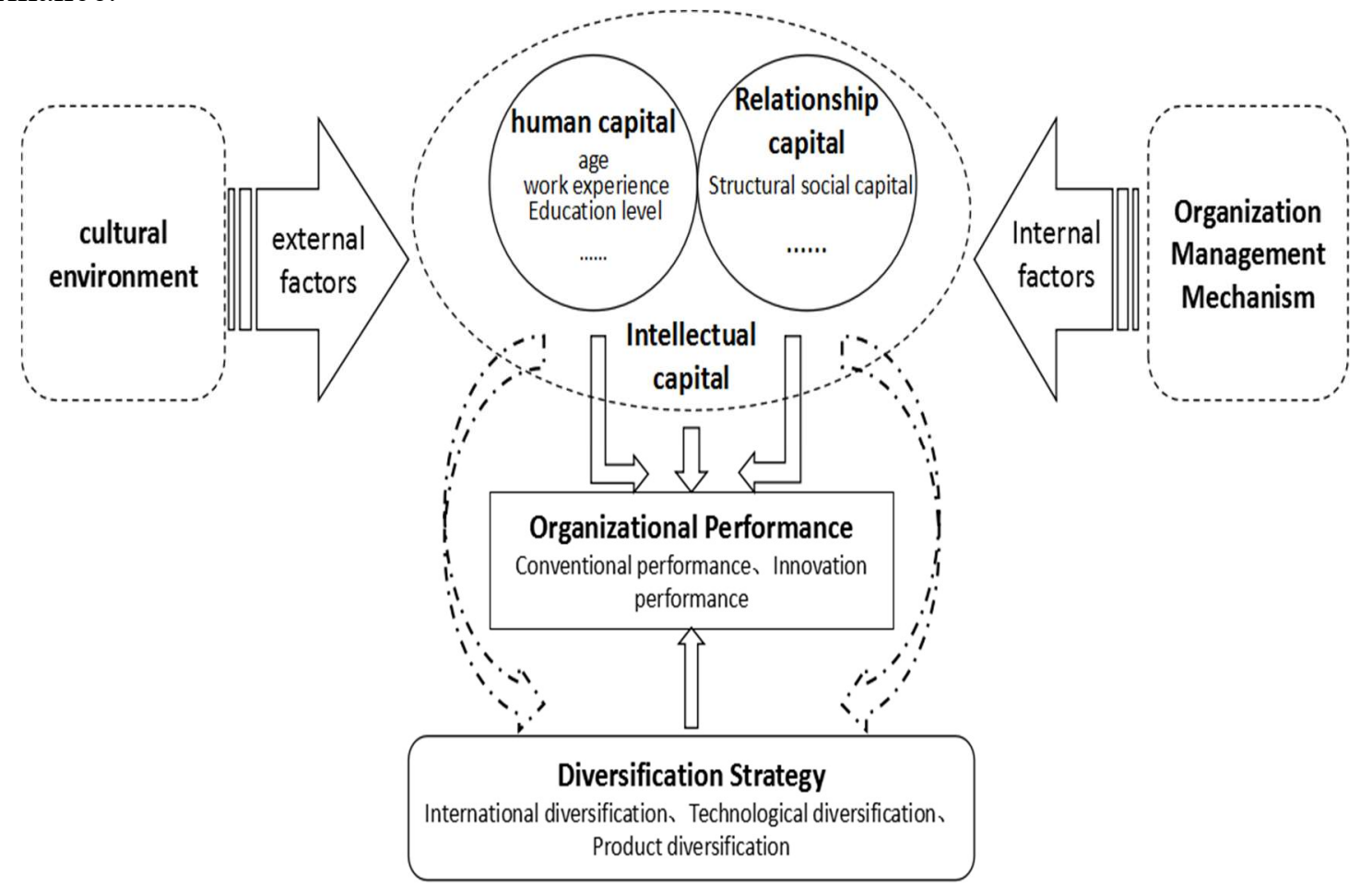

Figure 1. A model of the relationship among intellectual capital, strategy and corporate performance of top management teams

\section{Research Deficiency and Outlook}

First, in the future, we need to deeply study the relevant concepts of the intellectual capital of the executive team. Existing researches sum up the relevan concepts of the top management team's intellectual capital from the perspective of intangible assets, knowledge assets and innovation capabilities. These concepts need to be supplemented and improved further. Future research must discriminate relevant concepts such as intellectual capital, intangible assets and intellectual capital, and further clarify the relevant concepts of the intellectual capital of the senior management team.

Second, the future research needs to complement and improve the relationship mechanism between the intellectual capital, strategy and corporate performance of senior management team. The intellectual capital of the top management team is closely related to the selection and development of corporate strategy. Future research needs to further clarify the boundary conditions that the executive team's intellectual capital will affect the company's strategy, to guide the company's practice in a targeted manner. In addition, the research on the relationship between intellectual capital and corporate performance of senior management team is also relatively scarce, and scholars have not paid attention to the interaction between intellectual capital elements and corporate performance. Future research needs to define the internal mechanism of knowledge capital and enterprise performance of senior management team. 


\section{References}

[1]. Zhu Jinwei, Peng Yu. Study on the Effect of Top Management Team Characteristics on F-irm Performance-Based on the Internationalized Level of R-egulatory Effect. Soft Science.Vol.31(2017) No.06, p.81-85+95.

[2]. Li Wenchang, Dai Yijing. Investment Efficiency, Top Management Team Char-acteristics an-d Firm Performance: Path Model Analysis Based on Bootstrap Method. Accumulation a-nd Accounting Monthly. (2016) No06, p.85-91.

[3]. Pan Ailing, Yu Mingtao. An Empirical Study on the Relationship between To-p Managem-ent Team Characteristics and Financial Performance in Cultural Enterprises. Guangdong Social Sciences,(2013)No.07,p.5-14.

[4]. Díaz-Fernández MC, González-Rodríguez MR, Simonetti B.Top managementteam’s intellectual capital and firm performance. European Management Jo-urnal. Vol33(2015) No.05, p.322331.

[5]. Li Dayuan.The Sustainable Advantage of Enterprises in Uncertain Environm-ent[D]. Zhej-iang University,2008.

[6]. Amoremd, Garofaloo, Minichillia. Gender interactions with in the family firm. Management Science.Vol.60(2014) No.05, p.1083-1097.

[7]. Abdullah DF, SofianS. The Relationship between Intellectual Capital and Cor-porate Performance. Procedia-Social and Behavioral Sciences.Vol.40(2012) No.40, p.537-541.

[8]. Chen Mengyuan, Tang Guiyao. Research on the Relationship between Strategic Human ReSource Management and Corporate Entrepreneurship for Exec-utives. Journal of Shandon-g University Philosophy and Social Sciences.(201-6)No.05,p.85-93.

[9]. Jincai,Kaiqing,Limei,etal. Research on the evolution of dual network embeddi-ng in entrepreneurial growth-Taking Zhengtai Group and Wen Group as -examples. China Industrial Economy.(2012)No.08,p.122-134.

[10]. Yu Pengyi, Li Shanmin, Zhang Xiaobin. Study on Listed Companies' Equity Ownership Structure, Diversification and Corporate Performance. Management Science.(2005)No.01,p.79-83. 